\title{
Programação infanto-juvenil de qualidade: o caso da RTP2 de Portugal
}

\author{
Gabriela Borges ${ }^{1}$ \\ Universidade do Algarve \\ ga.borges@uol.com.br
}

\begin{abstract}
Resumo: Este trabalho pretende discutir questões de qualidade relacionadas com o segundo canal da televisão portuguesa, recentemente renomeado de RTP2. Na primeira parte, serão discutidos os diversos discursos de qualidade relacionados com as mudanças pelas quais o canal tem passado desde o ano de 2003. Na segunda parte, será discutida a programação destinada ao público infanto-juvenil, um dos mais importantes do canal e, na terceira parte, será analisada a série dramática Diário de Sofia, que apresenta uma proposta diferenciada dentro do panorama audiovisual português, que está atualmente tomado por novelas de qualidade duvidosa dedicadas a este público.
\end{abstract}

Palavras-chave: Televisão, Qualidade, RTP2

Resumen:Ese articulo tiene el propósito de discutir questiones de calidad relativas al segundo canal de la televisión portuguesa, recientemente denominado de RTP2. La primera parte discute los diversos discursos de calidad relacionados con los cambios por los quales el canal ha passado desde el año de 2003. La segunda parte discute la programación destinada ao público infantil y juvenil, uno de los más importantes del canal y, la tercera parte analiza la serie dramática Diário de Sofia, que presenta una propuesta diferente en el panorama audiovisual portugués, que actualmente está tomado por telenovelas de calidad dudosa dedicadas a ese público.

Palabras clave: Televisión, Calidad, RTP2

1 Publicitária, mestre e doutora em Comunicação e Semiótica pela PUC-SP, com estágios de investigação na Universidade Autônoma de Barcelona e no Trinity College Dublin. Atualmente realiza pós-doutoramento no Centro de Investigação em Ciências da Comunicação e Artes da Universidade do Algarve, onde também leciona nos cursos de Comunicação e Artes Visuais. Organizou recentemente a antologia Discursos e Práticas de Qualidade na Televisão, Ciccoma, Faro (no prelo) e a sua tese de doutoramento intitulada A poética televisual de Samuel Beckett também encontra-se no prelo para publicação pela Quasi Edições de Portugal. É co-editora da revista eletrônica Intermidias.com. Email: ga.borges@uol.com.br 
Résumé: Cet article a pour objectif l'analyse des questions de la qualité de la deuxième chaîne de télévision portugaise, récemment renommé RTP2. Dans la première partie de cet article, j'examinerai les divers discours de qualité qui s'encadrent dans les changements que la chaîne traverse depuis 2003. Dans la deuxième partie, je discutirai la programation pour l'audience infantojuvénile, une des plus importante pour la chaîne et, dans la dernière partie, janaliserai la série dramatique "Diário de Sofia" (le Journal de Sofia), laquelle présente un abordage différent dans le panorama audiovisuel portugais, actuellement envahi par des feuilletons quotidiens de qualité douteuse qui ciblent ce genre de public.

Mots-clés: Television, Qualité, RTP2

Abstract: The purpose of this paper is to discuss issues of quality in the recently renamed $R T P 2$ - the second Portuguese public television channel. In the first part of this article, I will examine various quality discourses related to the changes that the channel has witnessed since 2003. In the second part, I will discuss the channel's programming for children and teenagers, one of the most important for the channel and, in the third part, I will analyse the drama series "Diário de Sofia" (Sofia's Diary), which presents a different proposal in the Portuguese audiovisual scene, currently invaded by soap operas of questionable quality directed at this target audience.

Keywords: Television, Quality, RTP2.

\section{Da A:2 à RTP2}

Em dezembro de 2002, o modelo de radiodifusão de televisão proposto no documento "Novas Opções para o Audiovisual"2 apresentado pelo governo do Partido Social Democrata que estava no poder previa a entrega do segundo canal de serviço público à sociedade civil, cuja oferta de programas passaria a ser feita fora do âmbito do operador de serviço público e por intermédio de parcerias com diversas entidades e instituições.

\footnotetext{
${ }^{2}$ Disponível em <http://www.ics.pt/Ficheiros/serv_pub/Neo_Op_AV.pdf.> Consulta em 25/09/06.
} 
A entrega do segundo canal à sociedade civil foi bastante controversa $\mathrm{e}$ recebeu muitas críticas da opinião pública. Para o governo, a entrega à sociedade civil foi um meio-termo encontrado entre a privatização e a impossibilidade da continuidade de um canal público devido aos graves problemas financeiros com os quais o canal se encontrava. Para os formadores de opinião, nomeadamente os académicos e os jornalistas, o governo foi irresponsável pelo fato de não ter proposto um modelo pertinente de funcionamento do novo canal.

Pinto e Souza (2005:4) ressaltam que o governo não definiu claramente o papel da chamada "sociedade civil", que podia ser entendido como bem conviesse ao governo. Além disso, chamam a atenção para o carácter retórico do discurso do então Ministro da Presidência Morais Sarmento, que tentou convencer a sociedade de que o governo estava lhe oferecendo um bem precioso (a televisão pública) e que portanto só dependia de que esta se organizasse para fornecer conteúdos a serem veiculados pelo segundo canal.

No Contrato de Concessão Especial de Serviço Público assinado em 17 de novembro de 2003, a RTP2 foi substituída pela A 2: com uma concessão por um período de oito anos. $\mathrm{Na}$ fase inicial, a A 2: foi gerida pelo operador público de televisão, que garantia a emissão, os recursos humanos necessários à coordenação e operação e disponibilizou aos parceiros o acesso à sua capacidade de produção. $\mathrm{O}$ modelo definido apresentava uma gestão econômico-financeira autônoma em busca de auto-sustentação, cujo orçamento global foi estimado em 50\% do orçamento dedicado ao canal RTP2. O objectivo do progressivo desenvolvimento deste modelo era a "autonomização completa, traduzida na assunção total de responsabilidades pelo conjunto dos parceiros e na posterior atribuição da licença”.

A concessão especial tinha por objecto um serviço de programas com enfoque nos conteúdos de âmbito educativo, cultural, infantil e social. Para esse efeito foram definidas áreas de intervenção e parceiros institucionais que garantissem uma programação de qualidade dirigida a públicos segmentados abrangendo as seguintes áreas de actuação: cultura, ciência, investigação, inovação, ação social, desporto, confissões religiosas, produção independente, cinema 
português apoiado pelo ICAM, ambiente e defesa do consumidor e experimentalismo audiovisual.

Em outubro de 2003 o segundo canal da televisão pública foi entregue à algumas entidades da sociedade civil com uma nova imagem capitaneada pelo nome A 2:. O modelo adotado enfatizou o carácter mini-generalista, informativo e cultural, cujo objetivo era facilitar o acesso ao conhecimento por meio de uma programação de qualidade que respondesse às necessidades de públicos específicos, particularmente os jovens, as minorias e os cidadãos com dificuldades de comunicação ou mobilidade. A grade de programação contou com uma renovação de $76 \%$ do seu tempo de emissão a fim de atingir um público mais alargado do que aquele tradicionalmente atingido pela RTP2 e foi organizada a partir das quatro áreas temáticas: educativa, cultural, infantil e social.

Assim, a A 2: passou a ter um papel complementar em relação à RTP1 e aos outros canais do panorama audiovisual português, cuja missão era reforçar os princípios de universalidade, coesão e proximidade do serviço público de televisão por meio da diferença; defender a língua, a cultura e a história portuguesa; promover a integração do indivíduo na sociedade e a compreensão das suas instituições, da história das civilizações, da defesa do ambiente, das minorias e do papel das religiões3.

É possível destacar que o perfil da audiência esperado para o novo canal contava com um aumento de 17 para 25\% do público infantil (de 4-14 anos), um aumento de $3 \%$ no que diz respeito ao público feminino e uma diminuição de $4 \% \mathrm{e}$ 2\% dos públicos das faixas etárias de maiores de 55 anos e de 32-54 anos, respectivamente. A participação da sociedade civil na A 2: efectuou-se através da parceria com instituições tais como fundações, instituições de solidariedade social, ordens profissionais, associações, institutos, órgãos de comunicação social, universidades e O.N.G.s. e com produtoras independentes. As formas de participação estabelecidas foram as seguintes: fornecimento de programas ou seqüências para serem integradas em programas (em regime de produção ou co-produção); cedência de meios humanos ou materiais; apoio técnico e científico; cedência de direitos de

3 Disponível em <www.dois.tv/images/anova2.pdf >. Consulta em 10/10/o6. 
gravação e transmissão de programas e/ou eventos; patrocínios de espaços ou programas da grade.

Esta abertura à sociedade possibilitou o acesso do público aos valores, às temáticas e às realidades que, em geral, não encontram cobertura na mídia e disponibilizou uma nova oferta de programas para públicos novos e variados. Os parceiros participaram principalmente nos programas dos formatos Contentor4 Cidadania e Contentor Familiar e as produtoras independentes ficaram responsáveis pela produção da maioria dos programas nacionais e dos documentários. De fato, estas produziram 16 dos 18 programas de produção externa que integraram a grade de lançamento no final de 2003. Do ponto de vista da direção da A 2:, esta estratégia tinha como objectivo assegurar o revertimento do investimento público, estimulando assim a indústria audiovisual portuguesa e os profissionais nacionais.

Em termos de estratégias de comunicação5, os conceitos definidos para serem transmitidos com a criação da nova imagem foram os seguintes:

Abertura a Novos Canais,

Experimentalismo nos Formatos,

Representação das Minorias e Pequenos Segmentos,

Didatismo na Atuação Social,

Pluralidade de Conteúdos e Sentidos,

Multiplicidade de Intervenientes,

Ecletismo e Abrangência,

Ousadia no Conceito,

Inovação na Identidade,

Construção de uma Diferença,

$4 \mathrm{O}$ formato preferencial criado para evitar a fragmentação da grade. Cada contentor foi dividido em duas partes de 30 minutos dedicadas a um tema específico. Cada tema seria apresentado por um filme sobre o tema, seguido de um debate ou conversa informal com convidados sugeridos, preferencialmente, pelos parceiros.

5 Disponível em <www.dois.tv/images/anova2.pdf >. Consulta em 10/10/o6. 
Capitalização da A 2: como Marca,

Abertura do Acesso de Novos Segmentos da Sociedade.

Em relação à imagem de marca, o nome A 2 (a dois) demonstra parceria, abertura, simplicidade e um modelo que não está fechado numa instituição emissora, além de capitalizar ainda o património do antigo canal. A representação dos dois pontos (:) traduz a variedade de temáticas, personalidades e valores trazidos pelos novos parceiros, a versatilidade e a diversidade de representações geradas pelo novo formato e a riqueza da sociedade civil.

Sob a DireçãoGeral de Manuel Falcão, a programação da A 2: operou de novembro de 2003 a dezembro de 2005. No final de 2005 o diretor pediu exoneração do cargo devido à vitória do governo socialista, cujo programa previa a reintegração da A 2: numa concessão única de serviço público. Alegando à Alta Autoridade para a Comunicação Social ${ }^{6}$ que a extinção da concessão autônoma iria alterar a matriz do projeto e entravar a agilidade nas relações com os parceiros da sociedade civil, Manuel Falcão demitiu-se. Como balanço da sua gestão, Falcão refere-se à celebração de protocolos com 76 parceiros da sociedade civil e a negociação com mais duas dezenas e meia; a introdução da programação infantil, que se encontra equilibrada com a programação de outros canais em termos de qualidade; a afirmação de séries dramáticas de qualidade e de uma linha de documentários e o apoio à produção portuguesa7.

Em janeiro de 2006 Jorge Wemans é nomeado Diretor Geral com o intuito de, por um lado, dar continuidade a algumas estratégias implementadas pela gestão anterior e, por outro lado, promover algumas mudanças na forma de funcionamento e na grade de programação a partir de abril de 2006.

Em entrevista ${ }^{8}$ concedida em julho de 2006, Jorge Wemans afirma que o projeto inicial já estava em andamento quando assumiu a direção e a relação com o público e a opinião publicada estava muito melhor do que em 2004, quando não se

\footnotetext{
${ }^{6}$ Atualmente substituída pela ERC - Entidade Reguladora da Comunicação Social (<www.erc.pt>).

7 Parecer sobre a nomeação do diretor da A 2: de 16 de Janeiro de 2006. Disponível em <http://www.aacs.pt/bd/Deliberacoes/20060116a.htm>. Consulta em 20/o7/o6.

8 Entrevista concedida à autora do trabalho em 24 de julho de 2006.
} 
acreditava que o projeto seria sequer implementado. Considerando isso, a sua intenção concentrou-se em reforçar alguns aspectos positivos da programação que faziam sentido no panorama audiovisual português, mas que ainda não eram tão bem acolhidos pelo público e, principalmente, em simplificar a grade de programação. A nova direção deu continuidade ao bom relacionamento com os parceiros e investiu em algumas propostas que podiam melhorar a grade de programação e, consequentemente, a imagem da A 2:.

Em termos de qualidade, Wemans salienta que a sua maior preocupação é fazer com que todos os programas apresentem uma ótima qualidade em termos da narrativa e da imagem (a nível técnico e gráfico), a fim de que sejam reconhecidos como uma assinatura de qualidade da A 2:. Para isso, é necessário que todos os programas tenham qualidade suficiente para serem emitidos em horário nobre, mesmo que não sejam destinados a este horário da programação. Além disso, sugere que a intenção de melhorar o visual e o conteúdo dos programas, implementar um ritmo televisual e um bom gosto característico de uma produção de carácter audiovisual tem sido uma constante.

Em 22 de fevereiro de 2007, o Conselho de Ministros aprova a Proposta de Lei da Televisão9 $\mathrm{com}$ o intuito de rever a Lei da Televisão aprovada em 2003. No que diz respeito à A:2, um dos principais argumentos utilizados para esta revisão referese ao fato do segundo canal ter sido remetido para um estatuto atípico de concessão de serviço público e das condições de atribuição, renovação, revogação e modificação de licenças serem pouco exigentes. Sendo assim, propõe-se a inclusão obrigatória no serviço público de televisão dos canais RTP1, RTP2, RTP-Açores, RTP-Madeira e um ou mais canais internacionais, e a inclusão opcional da informação e interesse regional, memória, infanto-juvenil e conhecimento.

Considerando isso, a nova Lei da Televisão que está para ser aprovada na Assembléia da República estabelece que o futuro (retornado?) canal RTP2 oferecerá um serviço de programas generalista de âmbito nacional aberto à participação da sociedade civil, que apresenta uma programação de forte componente cultural e

\footnotetext{
9 Disponível em <http://www.portugal.gov.pt/NR/rdonlyres/9371998A-6B8D-4171-A38B41C26846BCAA/o/Anteprojecto_Prop_Lei_Televisao.pdf> Consulta em 28/01/o7.
} 
formativa, valorizando a educação, a ciência, a investigação, as artes, a inovação, a ação social, a divulgação das causas humanitárias, o desporto amador e o escolar, as confissões religiosas, a produção independente de obras criativas, o cinema português, o ambiente, a defesa do consumidor e o experimentalismo audiovisual. Além disso, e consoante tendências europeias, destaca-se entre as obrigações específicas do serviço público a programação infanto-juvenil, a transmissão de programas culturais, educativos e informativos para públicos específicos assim como de programas orientados para atividades de educação para as mídias.

Paradoxalmente, a A2: passará de um canal mini-generalista para um canal generalista, a RTP2, mas continuará a contemplar os interesses de públicos específicos. Não será focada no conhecimento como atualmente, mas continuará a valorizar a educação, a investigação, a ciência e as artes o que, de certa forma, equivale ao mesmo objectivo. Sendo assim, a proposta de lei ressalta que o segundo canal deve assegurar uma programação de grande qualidade, coerente e distinta dos demais serviços de programas televisivos de serviço público, em que participam entidades públicas e privadas com ação relevante nas áreas de atuação do canal.

Em relação ao que é relevante para este trabalho, é importante ressaltar que apesar da proposta para uma mudança no estatuto do segundo canal da televisão pública, em termos gerais as suas obrigações continuam bastante semelhantes. Entretanto, a preocupação de transmitir programas diretamente relacionados com a educação para as mídias por um lado inova e acrescenta valor à produção audiovisual e, por outro, vem ao encontro de diversas discussões e manifestações da opinião pública, da opinião publicada, da academia e do próprio Conselho da Europa. Além disso, deve-se referir que o artigo 52. ${ }^{\circ}$ da Proposta de Lei prevê que o contrato de concessão de serviço público defina os objetivos a alcançar pelo segundo canal, assim como os critérios qualitativos e quantitativos que assegurem a sua concretização e as respectivas formas de avaliação, o que representa um avanço no contexto português.

Em 13 de março de 2007, a A:2 voltou a ser inserida no âmbito do serviço público com a denominação RTP2. A nova imagem do canal apresenta cores em tons gradativos que vão desde o laranja ao castanho e preto. A mensagem do diretor Jorge 
Wemans que se encontra na novo site da internet ${ }^{10}$, agora novamente incorporado ao site da RTP, refere-se à nova RTP2 como uma alternativa no panorama audiovisual português, afirmando que esta "nasce de um acto de vontade, enuncia uma escolha e contém um convite". Vontade da equipa de comunicar o seu "entendimento da relação do canal com os públicos, os criadores e o espaço audiovisual.” A sua escolha é pela "qualidade, a inteligência, as margens e o experimentalismo". E o convite é para ver "além do óbvio, para captar segundos sentidos". O slogan adotado é o seguinte: "Quem vê, quer ver", o qual refere-se à criação de hábitos na audiência a partir de uma relação qualitativa com o canal, ou seja, quando o público assiste à RTP2 é porque quer ver aquilo que ainda ninguém lhe mostrou.

Apesar da mudança na imagem de marca, não se percebe até o momento mudanças significativas na grade de programação porque, de certa forma, as mudanças vêm sendo realizadas de forma gradativa desde que a nova direção tomou posse em janeiro de 2006. No que diz respeito à programação dedicada ao público infanto-juvenil a ser abordada neste trabalho, algumas estratégias vêm sendo adotadas a fim de melhorar a qualidade do serviço público oferecido para este público.

\section{A programação infantil e juvenil}

$\mathrm{Na}$ proposta apresentada para a reestruturação do canal em 2003 estava previsto que os programas infanto-juvenis ocupassem 19\% da grade de programação e fossem destinados à faixa etária dos 4-14 anos. Na opinião de Wemans esta faixa etária tão alargada provocou uma espécie de dispersão entre os programas destinados à este público. Por essa razão, a faixa etária de 4-10 anos foi estabelecida como o público-alvo infantil a partir de 2006. Sendo assim, o horário da manhã (7:0oh às 14:ooh), o período da tarde (16:0oh às 17:0oh) e da noite (19:40h às 20:40) ficaram ocupados durante toda a semana com o programa Zig Zag, que exibe um conjunto de animações estrangeiras que apresentam valores educativos de qualidade. Os programas que podem ser destacados são os seguintes: Caillou (Ruca), Abre-te

${ }^{10}$ Disponível em <http://rtp2.rtp.pt/rtp2.php>. Consulta em 03/04/o7. 
Sésamo, Little People, Noddy, O Mundo de Todd, As aventuras do Patinho. Além da série estrangeira Futurama, exibida aos domingos às 20:30h.

Além disso, o canal transmite programas infanto-juvenis produzidos por produtoras independentes. Os programas que se destacam são so seguintes:

Kulto: uma animação da joint venture O Estado de Sítio dedicada ao público dos 8 aos 12 anos, emitida aos sábados às 20:00h na RTP2. Cada episódio apresenta um tema específico relativo às novidades na área da música, videojogos, filmes, livros, história em quadrinhos, esporte e modos de vida, que são abordadas na linguagem do público por meio de entrevistas com pessoas diretamente ligadas à área em questão e das opiniões dos jovens.

Kulto é um programa descontraído, jovem e divertido que ainda apresenta um fator extremamente positivo, a forte interação com o público. Este é constantemente convidado a participar, por meio do envio de vídeos ou dos vários passatempos que são lançados. Entretanto, a inovação e utilização das novas tecnologias não está presente apenas nestes parâmetros, pois até mesmo os seus dois apresentadores são desenhos digitalmente animados que interagem com o público de uma forma bastante descontraída e com um visual moderno e apelativo. E também a página na internet11, que comunica-se com o público no sentido de oferecer prêmios e propor o envio de material audiovisual para ser transmitido no programa. Originalmente, o programa televisual foi concebido a partir da revista semanal Kulto veiculada pelo renomado jornal português Público, cujos personagens foram animados para o formato audiovisual. O projeto conta ainda com a Rádio Kulto disponível na internet12.

Pica (Programa de Intervenção em Canal Alternativo): um magazine cultural da produtora Gil \& Miller apresentado sob a forma de um programa de ficção com duração de 15 minutos. Este é exibido todos os dias da semana às 18:0oh na RTP2. Os conteúdos centram-se na apresentação de um bloco de notícias de 3 minutos, reportagens com interesse para jovens (com destaque para a tecnologia, jogos, música, literatura, cinema, teatro e desporto). O final de cada episódio apresenta um

\footnotetext{
${ }^{11}$ Disponível em <http://www.kulto.pt $>$. Consulta em 02/04/o7.

${ }^{12}$ Disponível em <http://cotonete.clix.pt/kulto/radio_kulto.asp >. Consulta em 03/o4/o7. 
jogo interativo que deve ser desenvolvido ao longo do tempo para uma plataforma na internet.

Em termos ficcionais, o programa é apresentado por dois irmãos, a Rita de 16 anos e o Jaime de 17 anos, que emitem, a partir de sua casa, um programa pirata que conseguem "hackar" no sinal de emissão da RTP2. O programa é feito por eles e pelos seus amigos espalhados pelo país, com quem contactam pela internet. A página do programa na internet13 disponibiliza informações tais como notícias, agenda, fórum, jogo, sinopse do programa e dos personagens, músicas, um trailler promocional, reportagens que podem ser vistas por intermédio do link para o site do you tube14. Pode-se ainda subscrever para receber uma newsletter por email. Neste sentido, o Pica é um programa feito por jovens para jovens e que se apresenta como uma alternativa de qualidade para aqueles que não queiram assistir às novelas infanto-juvenis exibidas neste mesmo horário no canal comercial TVI. Atualmente, a TVI emite a quarta temporada da novela Morangos com Açúcar, que tem uma média de audiência de $47 \%$.

É importante ressaltar que nos dados aferidos pela empresa de pesquisa de mercado, Marktest, consta que a A2: (atual RTP2) emitiu 61,1\% das horas de programação destinadas ao público jovem em 2006, em contraposição à 8,2\% da RTP1, 23,8\% da SIC e 6,8\% da TVI. Isso demonstra que o segundo canal tem se dedicado à transmissão de programas infanto-juvenis, porém a maior parte deles comprados no mercado internacional de televisão e emitidos no programa Zig Zag. Em função disso, a atual direção do canal investiu nos programas Kulto e Pica e continuou a investir em Diário de Sofia, que será analisado em detalhes no próximo tópico.

Como é possível perceber, o discurso político assim como o discurso institucional do canal enfatizam a oferta de programas de qualidade para o público infanto-juvenil. Entretanto, torna-se importante problematizar quais são os parâmetros a partir dos quais a qualidade em televisão pode ser pensada. Desde os anos 80 do século passado, este tema faz parte da agenda de debates tanto dos

\footnotetext{
${ }_{13}$ Disponível em <http://www.pica.pt>. Consulta em 02/04/07.

14 Disponível em <http://www.youtube.com>. Consulta em 02/04/07.
} 
estudos de televisão quanto da própria mídia, principalmente no que diz respeito à programação destinada aos públicos infantil e juvenil e ao papel desempenhado pela televisão na formação das mentalidades e na influência nos modos de ser e de estar das crianças e adolescentes.

Neste sentido, foram definidos alguns parâmetros de qualidade para a análise de programas dedicados a este público a partir de dois planos: da expressão e do conteúdo. Além disso, são considerados alguns critérios mais gerais pertinentes à mensagem audiovisual, conforme demonstrado a seguir:

\section{Plano da Expressão}

a) Ousadia e experimentalismo do formato audiovisual.

b) Originalidade e criatividade do formato.

c) Apelos visuais educativos.

\section{Plano do Conteúdo}

Cidadania e Democracia

Importância da produção de valores agregados na formação de mentalidades (escolha dos temas e abordagens)

> Promoção do desenvolvimento de valores cívicos e da consciência crítica junto ao público infantil e juvenil.

$>$ Abrangência da actuação do meio na construção de valores éticos

$>$ Informação agregada ao entretenimento no sentido de veicular narrativas que agreguem valores positivos

a) Participação do público

Estímulo à interatividade

Modos de recepção e produção de conteúdos pelas crianças e adolescentes por intermédio das participações efetivas na elaboração e desenvolvimento dos programas.

Utilização de outros meios e ferramentas de comunicação como a internet. 
$>$ Promoção da língua, cultura e valores nacionais

> Geração do interesse para facilitar a participação do público

$>$ Identificação da audiência com os temas e as propostas dos programas

b) Cumprimento das funções educativa, informativa e de divulgação (socialização do conhecimento).

Considerando isso, é importante referir ainda alguns critérios que devem nortear, de modo geral, a mensagem audiovisual quando se discute a qualidade dos programas a serem emitidos na televisão. São eles:

Relevância

Diversidade (opiniões, sujeitos representados, temas, geográfica, formatos e registros)

Eficiência na apresentação da proposta

Confiabilidade

Responsabilidade

Fontes

A partir dos parâmetros propostos, será analisada a série dramática Diário de Sofia, que se encontra na sua $3^{\text {a }}$ temporada.

\section{Diário de Sofia}

Diário de Sofia é uma série dramática exibida em episódios de 5 minutos de segunda à sexta-feira às 18:15h na RTP2, e em um compacto semanal de 25 minutos aos domingos na RTP1 e na RTP2. É uma produção da beActive Produções Interactivas, S.A, com autoria de Pedro Flores e realização de Gil Ferreira. Devido à originalidade do formato e ao modelo de emissão, em ecrã panorâmico formato 16x9, Diário de Sofia foi case study internacional no MIPTV, o maior mercado internacional de programas de televisão, realizado em Cannes e nomeado para o Mobile Entertainment Forum Awards na categoria de Inovação em 2004.

Diário de Sofia é emitido em vários continentes, Europa, América do Norte e do Sul e Ásia, sendo que a produtora beActive assinou acordos para a produção de 
versões locais na França, Espanha, Brasil, Áustria e Turquia. Em 2005, ocupou 34\% de share de mercado e contou com uma audiência média de 14,8\% encontrando-se muito bem posicionada frente à concorrência, que se efetua principalmente pela série Morangos com Açúcar, que não possui a mesma inovação em termos de formato e nem o mesmo trabalho de performance de atores. Em 2006 Diário de Sofia ocupou $39 \%$ de share de mercado.

Em termos mercadológicos, pode-se constatar que os programas Pica e Diário de Sofia ocupam meia hora da programação, das 18h às 18:30h, fazendo concorrência à novela Morangos com Açúcar. Porém, apesar dos programas apresentarem uma alternativa de qualidade para os mais jovens, esta iniciativa da RTP2 ainda se mostra bastante tímida, uma vez que a novela da TVI é exibida durante 2 horas, isto é, das $18 \mathrm{~h}$ às $20 \mathrm{~h}$.

Diário de Sofia é a primeira novela interativa e comunidade cross-media para adolescentes que gira em torno de uma história interativa em que o espectador/usuário pode decidir o desenvolvimento da história e que é oferecida simultaneamente em vários suportes, tais como a televisão, a internet, o rádio, a mídia impressa e o celular. No final de cada episódio o público é convidado a escolher o desenvolvimento da história, optando entre duas alternativas. A opção mais votada é exibida no dia seguinte. O público pode participar por telefone desde o final de cada episódio até ao início do episódio seguinte.

Na primeira temporada, emitida em 2003, o enredo começa com a história da vida de Sofia Afonso, uma adolescente de 17 anos que está no $11^{\circ}$ ano, quer estudar Medicina e mora com os pais, Alexandre e Helena, e os dois irmãos, Chico, de 20 anos e Mariana, de 14 anos. Como toda adolescente, sente-se perseguida pelos pais, acha que o irmão mais velho não ajuda nada em casa e implica com a irmã mais nova, que sempre pega as suas roupas e revistas sem pedir. As suas melhores amigas são a Rita e a Joana, e o seu melhor amigo é o Zeca. Agora tem uma nova amiga na turma, a Monica, que entrou na escola no $10^{\circ}$ ano e que a Sofia ainda não sabe se gosta muito dela. A sua grande inimiga, que está sempre a irritá-la, é a Bianca e o seu amigo, muito simpático e futuro namorado é o Joca, que joga râguebi e também está 
no $11^{\circ}$ ano. Os episódios relatam as suas diversas relações na escola com os amigos, no trabalho, na família e com o seu amigo e futuro namorado.

Na terceira temporada atualmente em exibição, Sofia tem 19 anos, repetiu o $12^{\circ}$ ano porque a média para entrar em Medicina era muito alta e ela não conseguiu por o.2. Sofia agora namora o Rui, que terminou $012^{\circ}$ ano, mas não quer fazer faculdade. Seus amigos mais próximos são a Rita, o Zeca, a Bianca e a Susana. A sua nova inimiga é a Teresa, que está sempre com as suas "damas de companhia", a Geninha e a Carla. Os episódios abordam as dificuldades da adolescência e exaltam o bom caráter de Sofia, que procura sempre ajudar os amigos, e que nunca mente, porque mentira não leva a lugar algum. Sofia sabe que a sua vida não é diferente da de outros adolescentes e, de certa forma, tenta ser um exemplo em termos de comportamento e boas ações.

Os créditos iniciais apresentam todos os personagens, um resumo do episódio do dia anterior e a opção que foi escolhida pela audiência para ser exibida. Um aspecto interessante do programa é que acompanha o crescimento de Sofia e os seus dilemas de adolescente, como o começo do primeiro namoro, o primeiro beijo, o primeiro emprego, enfim, as primeiras experiências da vida adulta de qualquer adolescente, que são cheias de inseguranças, medos e excitações. Pelo fato destes dilemas serem vividos por qualquer adolescente, o programa consegue gerar a identificação dos telespectadores. Enquanto na primeira temporada os dilemos do começo da juventude eram vividos por Sofia, agora ela já está mais "adulta” e tornouse num modelo de conduta para a sua irmã Mariana, que está sempre a lhe pedir conselhos, apesar de discutirem bastante também, porque a Mariana é muito "infantil".

A narração da história é feita em primeira pessoa, por Sofia, nos seus depoimentos e nas suas confidências para a câmera, e em terceira pessoa, por meio dos comentários e opiniões dos amigos e da família de Sofia. Tradicionalmente, os programas de ficção, diferentemente de outros formatos televisivos como o jornalístico, exibem a performance dos atores de forma naturalista e realista, ou seja, os personagens não olham para a câmera e atuam como se ela não estivesse presente, a fim de gerar a identificação e o envolvimento dos telespectadores com a história. 
Diário de Sofia não obedece a esta convenção herdada da narrativa clássica hollywoodiana e que também está presente nas telenovelas. A câmera registra uma certa escritura audiovisual, no sentido em que Sofia conversa olhando para a câmera de uma forma íntima, ou seja, como se estivesse escrevendo no seu diário. Consequentemente, a sua performance para a câmera faz com que os seus sentimentos e os seus pensamentos sejam também confidenciados aos telespectadores, que sentem-se como interlocutores dos seus dilemas.

Em termos de experimentação com a linguagem, o programa usa metaforicamente o seu próprio nome para propor a escritura de um diário audiovisual usando principalmente a câmera e os recursos de edição como ferramentas para agregar valores ao meio televisual. A leitura de um diário proporciona ao leitor apenas um ponto de vista, isto é, o ponto de vista do escritor. No caso do Diário de Sofia, o telespectador tem acesso ao seu ponto de vista, mas também dos seus amigos e familiares. Com isso, a história torna-se plural e o telespectador adquire a posição de sujeito omnisciente, porque os personagens não têm o mesmo conhecimento dos diferentes pontos de vista, e mostra-se capaz de escolher o que será melhor para Sofia no final de cada episódio. Neste sentido, apesar de não usar as convenções da narrativa clássica que são conhecidas por gerar a identificação da audiência, o programa Diário de Sofia ainda assim consegue a sua identificação e envolvimento por estes outros meios.

Outro ponto a ser ressaltado em relação ao interesse da audiência é o formato de exibição de 5 minutos diários que requer, simultaneamente, pouco tempo de atenção e a participação no final do episódio. Porém, a escolha entre apenas duas alternativas não deixa de ser redutora. A participação no programa se efetiva apenas como escolha e não ocorre nenhum tipo de intervenção e interação ativa da audiência. Em outros meios audiovisuais, como nos jogos multimídia, o público juvenil está acostumado a interagir com a narrativa e não somente escolher entre algumas alternativas, mas ao que tudo indica, apesar da televisão fagocitar diversas características de outros meios, ainda não incorporou completamente este elemento de participação efetiva que no futuro pode vir a mudar o panorama televisual. Por 
outro lado, o Fórum da Sofia e da Mariana ${ }^{15}$ na internet permite que os telespectadores dêem as suas opiniões e sugestões a respeito de temas a serem abordados no programa.

Em relação à narrativa em terceira pessoa, é possível notar um tom testemunhal quando os amigos e familiares da Sofia falam sobre ela. Os enquadramentos da câmera apresentam características documentais com grafismos no ecrã que transmitem a ideia de que são pontos de vista sobre as ações e o jeito de ser e de estar de Sofia. A edição de imagens apresenta-se fragmentada, pelo próprio tempo de exibição, 5 minutos diários e também porque além de ser uma característica da televisão, é bem reconhecida pelo público-alvo, que tem como referência habitual a rapidez da edição das imagens da MTV e dos jogos multimídia.

Entretanto, a série compartilha com outros produtos audiovisuais congêneres o mercado audiovisual não apenas português, mas também internacional, e disponibiliza uma variedade de produtos derivados, como DVD dos episódios, CD com as músicas da trilha sonora, os 11 livros com as histórias do Diário de Sofia, além do site na internet ${ }^{16}$ que oferece informações como as sinopses e os vídeos dos episódios, a caracterização do perfil dos personagens, fórum de discussão, chats, clube de fãs, passatempos e os links para os blogs ou fóruns dos outros personagens, como por exemplo da Mariana. Os episódios transmitidos na televisão são posteriormente disponibilidos no site para serem visionados pelos fãs que não puderam assisti-los.

No plano do conteúdo, é importante enfatizar que o enredo de Diário de Sofia apresenta aquilo que Mepham (1996:56-60) refere-se como uma das principais características dos programas de ficção de qualidade, que é a de promover as narrativas úteis, aquelas que agregam valor para os espectadores, fazendo com que dêem asas à imaginação. As narrativas úteis podem ser colocadas em uso muitas vezes inconscientemente, estimulando o processo de auto-conhecimento do indivíduo e as suas relações sociais. Nesse sentido, os programas de ficção apresentam grande relevância cultural e devem ser definidos em termos de critérios éticos, oferecendo ao

\footnotetext{
15 Disponível em <http://www.diariodemariana.com/index.php>. Consulta em 02/04/07.

${ }^{16}$ Disponível em < http://www.diariodesofia.sapo.pt>. Consulta em 02/04/07.
} 
telespectador histórias que podem ser úteis no desenvolvimento tanto da personalidade quanto da vida social. Se por um lado as narrativas podem ser úteis para entreter e desviar a atenção da vida real, por outro lado elas podem chamar a atenção para questões de ordem pessoal, política, social e cultural. Isto porque as narrativas informam as pessoas sobre os problemas e as soluções, as oportunidades e os perigos, as virtudes e os vícios vivenciados pelos personagens que, de certa forma, são comuns a qualquer ser humano.

Á título de exemplo, podem ser mencionadas duas situações referentes aos episódios 13,15 , respectivamente, da $3^{\text {a }}$ temporada da série. A primeira delas diz respeito ao evento em que a personagem Mariana, irmã de Sofia, escreve uma crônica para participar do concurso para o editor do jornal da escola, que está aberto somente para os alunos do $12^{\circ}$ ano, e ela se encontra no $10^{\circ}$ ano. Ao ser descoberta pela diretora, Mariana é punida com o castigo de fazer a limpeza do banheiro da escola durante uma semana. A segunda refere-se ao evento em que a personagem Teresa copia o trabalho de português da melhor amiga de Sofia, a Rita. Sofia e Rita são punidas pela professora, que pensa que elas estão mentindo, entretanto, depois de alguns contratempos as duas meninas conseguem provar para a professora que quem tinha copiado o trabalho era a Teresa. Sendo que esta tem de apresentar o trabalho para a turma, passando muita vergonha por não saber explicá-lo e como resultado recebe um zero.

Sendo assim, um programa de qualidade deve oferecer ao telespectador narrativas que estimulem a imaginação e não sejam previsíveis, como as conhecidas histórias em que o bem vence o mal, que não apresentam nenhuma complexidade e o final é sempre feliz.

\section{Considerações finais}

É importante ressaltar que o segundo canal da televisão pública portuguesa sofre os revezes, como a maioria dos seus congêneres europeus, dos ventos das mudanças políticas que ocorrem a cada quatro anos no país. Isso dificulta a constituição de um canal com uma proposta de comunicação sólida que possa ser desenvolvida ao longo dos anos. Mesmo assim, os dois projetos de comunicação e as 
duas grades de programação veiculadas nesses últimos quatro anos demonstraram que a qualidade televisual é um dos aspectos a ser mais do que considerado, mas também aperfeiçoado no discurso audiovisual emitido pelo canal. A mudança da denominação e da conseqüente imagem da RTP2 é bastante recente, pelo que se espera que nos próximos anos seja possível analisar em que medida a sua reinserção no serviço público de televisão trouxe (ou não) melhoras substanciais no que diz respeito ao formato e às propostas dos programas, principalmente aqueles destinados ao público infanto-juvenil.

Em relação aos parâmetros de qualidade definidos para os planos da expressão e do conteúdo, pode-se constatar que a inovação no formato audiovisual diferencia a série Diário de Sofia de outras propostas destinadas ao público infantojuvenil. Por outro lado, percebe-se que apenas alguns dos parâmetros relativos ao plano do contéudo podem ser ressaltados, conforme foi discutido acima. Isto não deve ser visto como algo negativo, porque a definição dos parâmetros de qualidade propostos para a análise de programas infanto-juvenis leva em consideração que dificilmente um só programa apresente todos eles. Sendo assim, o intuito da pesquisa que se encontra em desenvolvimento é de que os parâmetros sejam pensados tanto em relação a cada um dos programas como da programação emitida pelo canal. Neste sentido, a análise mais aprofundada dos outros programas mencionados neste trabalho permitirá que outros aspectos sejam discutidos.

Para finalizar, é importante referir que este trabalho apresenta resultados parciais do projeto de investigação de pós-doutoramento intitulado "TV em cena: estudo de parâmetros de qualidade para a análise de programas”, que está a ser desenvolvido com financiamento da Fundação para a Ciência e a Tecnologia/MCTES Portugal e com a colaboração do Grupo de Estudos de Televisão de Qualidade do Ciccoma, composto por alunos do $3^{\circ}$ ano do curso de Ciências da Comunicação da Universidade do Algarve. 


\section{Bibliografia}

Borges, G. (2005): "A discussão do conceito de qualidade no contexto televisual britânico" em Líbero Revista Acadêmica da Pós-Graduação da Faculdade Casper Líbero, São Paulo, Ano VII, No $13 / 14$.

-- (no prelo): "Discursos de qualidade: a programação da A 2: portuguesa". Borges, G. e Baptista, Vítor Reia (org.). Discursos e práticas de qualidade na televisão da Europa e América Latina. Faro, Ciccom/Universidade do Algarve.

Broadcasting Research Unit. (1989): Quality in television: Programmes, Programme-makers, systems. Londres, John Libbey.

Mepham, J. (1990): “The Ethics of quality in television" em Mulgan, G. (org.): The Question of quality. Londres, British Film Institute.

Pinto, Manuel (coord.) (2005): Televisão e Cidadania. Contributos para o debate sobre o serviço público. Porto: Campo das Letras.

e Souza, Helena (2005): Media policy, economics and citizenship: an analysis of a peculiar model for participatory public service television. [online]. <http://hdl.handle.net/1822/3076> [Consulta em 10/01/2006].

\section{Outras fontes:}

Anteprojeto de Lei da Televisão. Disponível em <http://www.portugal.gov.pt/NR/rdonlyres/9371998A-6B8D-4171-A38B41C26846BCAA/o/Anteprojecto_Prop_Lei_Televisao.pdf> Consulta em 28/01/o7.

Fórum da Sofia e da Mariana. Disponível em <http://www.diariodemariana.com/index.php>. Consulta em 02/04/07.

Parecer sobre a Nomeação do Diretor da A 2: de 16 de Janeiro de 2006. Disponível em $<$ http://www.aacs.pt/bd/Deliberacoes/20060116a.htm>. Consulta em 20/07/06.

Relatório Novas Opções para o Audiovisual. Presidência do Conselho de Ministros, Lisboa, 2002. Disponível em $<$ http://www.ics.pt/Ficheiros/serv pub/Neo Op AV.pdf. $>$ Consulta em 25/09/06.

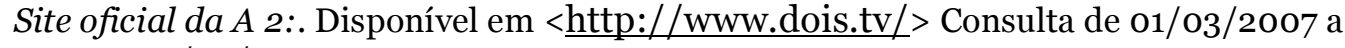
20/03/2007.

Site oficial do programa Diário de Sofia. Disponível em $<$ http://www.diariodesofia.sapo.pt $>$ Consulta em 01/04/2007.

Site oficial do programa Kulto.Disponível em < http://www.kulto.pt>. Consulta em 02/04/07.

Site oficial do programa Pica. Disponível em < http://www.pica.pt $>$. Consulta em 02/04/07.

Site oficial da RTP2. Disponível em < http://rtp2.rtp.pt/rtp2.php>. Consulta em 03/o4/o7. 